\title{
Pentadecapeptide BPC 157 counteracts thrombosis and all manifestations of $48 h$-inferior cava vein ligation (syndrome) in rats
}

\author{
Predrag Sikirić*, Jakša Vukojević, Marko Siroglavić, Katarina Kašnik, Tamara Kralj, Duje Stančić, \\ Darko Kolarić, Śven Seiwerth \\ University of Zagreb School of Medicine, Zagreb, Croatia
}

\begin{abstract}
Background: We implicated stable gastric pentadecapeptide BPC 157 particular beneficial combining (bleeding/ thrombocytopenia after amputation and/or anticoagulants and aspirin and abdominal aorta anastomosis-thrombosis both counteracted; wound healing capacity; endothelium protection; interactions with NO-system in different models and various species; particular effect on blood pressure; anti-arrhythmic effect) to counteract deep vein thrombosis (DVT) and inferior caval vein (ICV)-syndrome.
\end{abstract}

Methods: Surgery. In deeply anaesthetized female Wistar rats the ICV was exposed via a midline laparotomy, dissected at the level of the right ovarian vein, and then ligated up to right ovarian vein, and rats were randomly divided into different groups for further experiments and assessments (ICV and aorta blood pressure recordings, ECG recordings, heart rate, blood vessel collateralization, bleeding, vein wall analysis, thermography, indirect ophtalmoscopy of retina). BPC 157 was given as $1 \mathrm{ml}$ bath (thrombosis; blood pressure; heart rate; collaterization); or intraperitoneally (bleeding). Delayed therapy. BPC $157(10 \mu \mathrm{g} / \mathrm{kg}, 10 \mathrm{ng} / \mathrm{kg})$ was given intraperitoneally, at advanced ligation-time points: $1 \mathrm{~h} ; 2 \mathrm{~h}$;

\section{Received: $24^{\text {th }}$ Apr 2014}

*Address for correspondence: Zavod za farmakologiju Medicinskog fakulteta Sveučilišta u Zagrebu, Šalata 11, HR-10000 Zagreb, Croatia.

Phone: +385-1-4566-833

E-mail: sikiric@mef.hr
$6 \mathrm{~h}, 24 \mathrm{~h}, 48 \mathrm{~h}$. Controls simultaneously received an equivolume of saline $(5 \mathrm{ml} / \mathrm{kg})$. Assessments were carried out at $10 \mathrm{~min}, 30 \mathrm{~min}, 1 \mathrm{~h}, 6 \mathrm{~h}, 24 \mathrm{~h}$ and $48 \mathrm{~h}$ thereafter.

Results: In rats with $48 \mathrm{~h}$-ICV ligation, BPC 157 salutary effect was elicited at any point of 48h-ligation-time. BPC 157 $(10 \mu \mathrm{g}, 10 \mathrm{ng} / \mathrm{kg}$, both early (i.e., $1 \mathrm{ml}$ bath at $5 \mathrm{~min}$ ligationtime) and delayed therapy (intraperitoneally)) counteracts thrombosis and all manifestations of $48 \mathrm{~h}$-ICV ligation (syndrome), i.e., instead progressive DVT, the length and weight of the formed clot considerably less; instead thickened, intima as thick as the nuclei of normal spindle-shaped endothelial cells; instead substantially increased bleeding with an injury and thrombocytopenia, BPC 157-rats bleed less, and have no thrombocytopenia; blood pressure brought to normal values in both ICV and abdominal aorta, vein hypertension and systemic hypotension counteracted, almost normal eye fundus, tachycardia normalized, attenuated ischemia, gross organ congestion greatly prevented or reduced, collaterals and redistribution of otherwise trapped blood volume rapidly presented, and thereby attenuated drinking, leg edema and cyanosis.

Conclusions: Pentadecapeptide BPC 157 counteracts DVT and all manifestations of 48h-ICV ligation in rats.

KEYWORDS: BPC 157, deep vein thrombosis, inferior cava vein ligation, rats.

CITATION: Cardiol Croat. 2014;9(5-6):258.

\section{Literature}

1. Sikiric P, Seiwerth S, Rucman R, et al. Stable gastric pentadecapeptide BPC 157-NO-system relation. Curr Pharm Des. 2014;20(7):1126-35.

2. Stupnisek M, Franjic S, Drmic D, et al. Pentadecapeptide BPC 157 reduces bleeding time and thrombocytopenia after amputation in rats treated with heparin, warfarin or aspirin. Thromb Res. 2012;129(5):652-9. 